\title{
PENGARUH BUDAYA ORGANISASI DAN DISIPLIN KERJA TERHADAP KINERJA KARYAWAN DI DIVISI LIKUID PADA PT.EAGLE INDO PHARMA-TANGERANG
}

\author{
Darmadi $^{1}$, N. Lilis Suryani ${ }^{2}$ Ratna Sari ${ }^{3}$ \\ Fakultas Ekonomi, Universitas Pamulang \\ Email: dosen02445@unpam.ac.id
}

\begin{abstract}
Purpose. This study aims to determine the effect of culture on performance employee in the liquid division at PT Eagle Indo Pharma-Tangerang, to determine the effect of work discipline on performance employee in the liquid division at PT Eagle Indo PharmaTangerang, and to determine the effect of culture and work discipline on performance employee in the liquid division at PT Eagle Indo Pharma-Tangerang.

Methods. This research method uses quantitative methods with descriptive and associative approaches. The data collection method used was a questionnaire questionnaire. Analysis of the data used is the validity test, reliability test, normality test, multicollinearity test, heterokedasticity test, simple linear regression, multiple linear regression, correlation coefficient, coefficient of determination, and hypothesis testing.
\end{abstract}

Findings. Hypothesis testing partially the culture variable $\left(X_{1}\right)$ obtained tcount $>$ ttable $(30,7191>2.001)$ it was also strengthened with a significance value of $0,000<0.05$. This means that culture has a significant effect on employee performance. The statistical test of work discipline variable $\left(X_{2}\right)$ obtained the value of tcount $>$ ttable $(40,651>2,001)$ it was also strengthened with a significance value of 0,000 <0.05. This means that work discipline has a significant effect on employee performance. Testing the hypothesis simultaneously obtained value of Fcount $>$ Ftable or $(74,894>3.15)$ this is also strengthened by the probability value of significance of 0,000<0.05. So it can be said that culture and work discipline have a significant simultaneous effect on employee performance The coefficient of determination obtained $R$ Square value of 0,694, meaning that the variables of culture and work discipline together have an influence contribution of $69,4 \%$ on employee performance. While the remaining 30,6\% is influenced by other factors not examined in this study.

Implication. Leaders further increase their supervision of employees and employees are more aware of the importance of implementing Standard Operating Procedures (SOPs) at work. Thus it will produce quality work results.

Keywords. Culture, Work Discipline, Employee Performance.

\begin{abstract}
ABSTRAK
Tujuan. Penelitian ini bertujuan untuk mengetahui pengaruh budaya organisasi terhadap kinerja karyawan di divisi likuid pada PT.Eagle Indo Pharma-Tangerang, untuk mengetahui pengaruh disiplin kerja terhadap kinerja karyawan di divisi likuid pada PT.Eagle Indo Pharma-Tangerang, dan untuk mengetahui pengaruh budaya organisasi dan disiplin kerja terhadap kinerja karyawan di divisi likuid pada PT.Eagle Indo PharmaTangerang.
\end{abstract}


Metode. Metode penelitian ini menggunakan metode kuantitatif dengan pendekatan deskriptif dan asosiatif. Metode pengumpulan data yang digunakan adalah angket kuesioner. Analisis data yang digunakan yaitu uji validitas, uji reliabilitas, uji normalitas, uji multikolinearitas, uji heterokedastisitas, regresi linier sederhana, regresi linier berganda, koefisien korelasi, koefisien determinasi, dan uji hipotesis.

Hasil. Pengujian hipotesis secara parsial variabel budaya organisasi (X1) diperoleh nilai thitung > ttabel $(30,719>2,001)$ hal tersebut juga diperkuat dengan nilai signifikansi $0,000<0,05$. Artinya budaya organisasi berpengaruh signifikan terhadap kinerja karyawan. Uji statistik variabel disiplin kerja (X2) diperoleh nilai nilai thitung $>$ ttabel $(40,651>2,001)$ hal tersebut juga diperkuat dengan nilai signifikansi $0,000<0,05$. Artinya disiplin kerja berpengaruh signifikan terhadap kinerja karyawan. Pengujian hipotesis secara simultan diperoleh nilai Fhitung $>$ Ftabel atau $(74,894>3,15)$ hal ini juga diperkuat dengan nilai probability signifikansi sebesar 0,000 $<0,05$. Maka dapat diakatakan bahwa budaya organisasi dan disiplin kerja berpengaruh signifikan secara simultan terhadap kinerja karyawan. Koefisien determinasi diperoleh nilai $R$ Square sebesar 0,694, artinya variabel budaya organisasi dan disiplin kerja secara bersama-sama memiliki kontribusi pengaruh sebesar $69,4 \%$ terhadap kinerja karyawan. Sedangkan sisanya sebesar 30,6\% dipengaruhi oleh faktor lain yang tidak diteliti dalam penelitian ini.

Implikasi. Pemimpin lebih meningkatkan pengawasannya terhadap para karyawan dan karyawan lebih menyadari akan pentingnya penerapan Standar Operasional Prosedur (SOP) dalam bekerja. Dengan demikian akan menghasilkan hasil kerja yang berkualitas.

Kata Kunci. Budaya Organisasi, Disiplin Kerja, Kinerja Karyawan.

\section{Pendahuluan}

PT. Eagle Indo Pharma atau yang lebih dikenal dengan nama CAP LANG berdiri sejak tahun 1973. CAP LANG terus melakukan transformasi hingga menjadi perusahaan seperti yang dikenal sekarang. Dengan pengalaman lebih dari 38 tahun, perusahaan ini tetap konsisten melayani dan meningkatkan kesehatan masyarakat melalui penyediaan produk-produk farmasi OTC (Over the Counter) yang berkualitas tinggi, efektif, dan aman digunakan.

Dari hasil pra - survey penulis mendapatkan data target yang dicapai dalam 3 tahun terakhir di tahun 2018 sebagai berikut.

Tabel 1. Target Karyawan di Divisi Likuid pada PT. Eagle Indo Pharma

\begin{tabular}{|c|c|c|c|}
\hline \multirow{2}{*}{ Produk } & \multicolumn{3}{|c|}{ Tahun } \\
\cline { 2 - 4 } & $\mathbf{2 0 1 6}$ & $\mathbf{2 0 1 7}$ & $\mathbf{2 0 1 8}$ \\
\hline Mkp 30 ml & 13.256 box & 11.058 box & 10.256 box \\
Mkp $60 \mathrm{ml}$ & 19.058 box & 17.550 box & 16.008 box \\
Tl $30 \mathrm{ml}$ & 12.025 box & 12.005 box & 11.256 box \\
Tl $60 \mathrm{ml}$ & 18.225 box & 16.035 box & 10.925 box \\
\hline
\end{tabular}

Sumber : PT. Eagle Indo Pharma, 2020

Berdasarkan tabel 1 di atas menujukkan bahwa ada penurunan target pada tahun 2018, penurunan target tersebut di karnakan karyawan yang rajin sebelumnya mencontoh karyawan yang bermalas - malasan. Kurangnya rasa tanggung jawab terhadap pekerjaan akan kesadaran dan kewajiban untuk melaksanakan pekerjaan yang diberikan oleh perusahaan.

Salah satu factor lainnya yang mempengaruhi adalah factor disiplin kerja. Disiplin adalah suatu hal yang mutlak harus ditanamkan pada setiap karyawan di perusahaan baik 
tingkat bawah sampai ditingkat atas. Hal yang paling dasar dalam disiplin karyawan adalah manajemen waktu, dalam hal ini yaitu jam kerja dan kehadiran. Apabila waktu tersebut sering dilanggar, dapat dikatakan bahwa para karyawan menjadi tidak disiplin sehingga mengakibatkan penurunan kualitas kinerja karyawan. Untuk memelihara dan meningkatkan disiplin yang baik adalah hal yang sulit, karena banyak factor yang mempengaruhinya. Karena dalam kedisiplinan perlunya rasa kesadaran diri, kesadaran yang dimaksud adalah sikap seseorang yang secara sukarela menaati semua peraturan dan sadar akan tugas dan tanggung jawab.

Tabel 2. Absensi Karyawan di Divisi Likuid pada PT. Eagle Indo Pharma

\begin{tabular}{|c|c|c|c|c|c|c|c|}
\hline \multirow[b]{2}{*}{ Tahun } & \multirow[b]{2}{*}{ Bulan } & \multirow[b]{2}{*}{$\begin{array}{c}\text { Jumlah } \\
\text { Karyawan }\end{array}$} & \multirow[b]{2}{*}{$\begin{array}{c}\text { Jumlah Hari } \\
\text { Kerja }\end{array}$} & \multicolumn{3}{|c|}{ Alasan Ketidakhadiran } & \multirow[b]{2}{*}{$\begin{array}{l}\text { Jumlah } \\
\text { Masuk }\end{array}$} \\
\hline & & & & Sakit & Izin & Alpa & \\
\hline \multirow{12}{*}{2016} & Januari & 62 & 23 & 6 & 0 & 10 & 46 \\
\hline & Febuari & 62 & 20 & 5 & 10 & 2 & 45 \\
\hline & Maret & 62 & 23 & 6 & 5 & 2 & 59 \\
\hline & April & 62 & 22 & 4 & 6 & 0 & 52 \\
\hline & Mei & 62 & 23 & 0 & 4 & 0 & 58 \\
\hline & Juni & 62 & 22 & 4 & 7 & 0 & 51 \\
\hline & Juli & 62 & 23 & 6 & 0 & 4 & 52 \\
\hline & Agustus & 62 & 23 & 3 & 0 & 6 & 53 \\
\hline & September & 62 & 22 & 0 & 3 & 14 & 45 \\
\hline & Oktober & 62 & 23 & 0 & 1 & 12 & 49 \\
\hline & November & 62 & 22 & 1 & 0 & 0 & 61 \\
\hline & Desember & 62 & 23 & 4 & 0 & 0 & 58 \\
\hline \multirow{12}{*}{2017} & Januari & 62 & 23 & 5 & 5 & 10 & 42 \\
\hline & Febuari & 62 & 20 & 5 & 3 & 4 & 50 \\
\hline & Maret & 62 & 23 & 7 & 5 & 7 & 43 \\
\hline & April & 62 & 22 & 1 & 1 & 0 & 60 \\
\hline & Mei & 62 & 23 & 0 & 6 & 0 & 56 \\
\hline & Juni & 62 & 22 & 0 & 8 & 7 & 47 \\
\hline & Juli & 62 & 23 & 0 & 5 & 5 & 52 \\
\hline & Agustus & 62 & 23 & 7 & 0 & 8 & 47 \\
\hline & September & 62 & 22 & 5 & 1 & 0 & 56 \\
\hline & Oktober & 62 & 23 & 1 & 0 & 1 & 60 \\
\hline & November & 62 & 22 & 1 & 0 & 1 & 60 \\
\hline & Desember & 62 & 23 & 7 & 4 & 11 & 40 \\
\hline \multirow{12}{*}{2018} & Ianuari & 62 & 23 & 3 & 6 & 13 & 38 \\
\hline & Febuari & 62 & 20 & 4 & 4 & 10 & 44 \\
\hline & Maret & 62 & 23 & 0 & 5 & 4 & 53 \\
\hline & April & 62 & 22 & 0 & 8 & 9 & 45 \\
\hline & Mei & 62 & 23 & 7 & 6 & 0 & 49 \\
\hline & Iuni & 62 & 22 & 8 & 0 & 2 & 52 \\
\hline & juli & 62 & 23 & 8 & 0 & 0 & 54 \\
\hline & Agustus & 62 & 23 & 5 & 6 & 0 & 51 \\
\hline & September & 62 & 22 & 6 & 4 & 15 & 37 \\
\hline & Oktober & 62 & 23 & 3 & 7 & 6 & 46 \\
\hline & November & 62 & 22 & 8 & 3 & 15 & 36 \\
\hline & Desember & 62 & 23 & 3 & 8 & 1 & 50 \\
\hline
\end{tabular}

Sumber : PT. Eagle Indo Pharma, 2020

Dari data tersebut tergambar singkat kedisiplinan karyawan berdasarkan hari kerja dan jumlah karyawan sebagai salah satu instrumen pelaksanaan disiplin termasuk dalam kategori kurang disiplin. Taat terhadap peraturan perusahaan merupakan instrument yang penting juga dalam menilai tingkat kedisiplinan karyawan. Namun masih ditemukan beberapa karyawan yang tidak menaati peraturan perusahaan tersebut seperti perlengkapan kerja yang tidak terpakai dengan sempurna. Perlu adanya pengawasan dan bimbingan pemimpin agar disiplin kerja karyawan lebih baik dan dapat meningkatkan kinerja karyawan dengan mematuhi peraturan kerja yang ada.

Kinerja mempunyai arti penting bagi pegawai, adanya penilaian kinerja berarti pegawai mendapat perhatian dari atasan, disamping itu akan menambah gairah kerja pegawai 
karena dengan penilaian kinerja ini mungkin pegawai yang berprestasi dipromosikan, dikembangkan dan diberi penghargaan atas prestasi, sebaliknya pegawai yang tidak berprestasi kemungkinan promosi akan di tinjau ulang. Masalah mengenai budaya organisasi dan kinerja karyawan menjadi penting karena menyangkut dengan unsur manusia dan sistem nilai lingkungan kerjanya.

Tabel 3. Data Presentase Pencapaian Target di Divisi Likuid pada PT. Eagle Indo Pharma

\begin{tabular}{|c|c|c|c|c|}
\hline No & Tahun & TargetPencapaianFee & RealisasiPencapaian & Presentase \\
\hline 1 & 2016 & Rp. 1.116 .096 .000 & Rp. 817.040 .400 & $73 \%$ \\
2 & 2017 & Rp.1.116.096.000 & Rp. 765.776 .400 & $69 \%$ \\
3 & 2018 & Rp.1.116.096.000 & Rp.511.126.800 & $46 \%$ \\
\hline
\end{tabular}

Sumber : PT. Eagle Indo Pharma, 2020

Dari table 3 di atas dapat dilihat pencapaian target di Divisi Likuid Pada PT.Eagle Indo Pharma Tangerang selama periode 3 tahun yaitu pada tahun 2016 untuk target tercapai 73\%. Dan pada tahun 2017 pencapaian targer 69\% dan pada tahun 2018 pencapaian target sebesar 46\%. Dengan demikian penulis menyimpulkan bahwa kinerja di divisi likuid pada PT.Eagle Indo Pharma Tangerang belum mencapai hasil yang maksimal.

Berdasarkan pemaparan di atas maka penulis tertarik melakukan penelitian dengan judul "Pengaruh Budaya Organisasi dan Disiplin kerja Terhadap Kinerja Karyawan Di Divisi Likuid Pada PT. Eagle Indo Pharma Tangerang".

\section{Kajian Pustaka dan Hipotesis}

Budaya Organisasi. Menurut Edison dkk (2016:119) mengatakan, bahwa "Budaya organisasi merupakan hasil dari suatu proses mencairkan dan meleburkan gaya budaya dan atau perilaku tiap individu yang dibawa sebelumnya ke dalam sebuah norma-norma dan filosofi yang baru, yang memiliki energy serta kebanggaab kelompok dalam menghadapi sesuatu dan tujuan tertentu". Sedangkan pendapat Wheel dan Hunger dalam Mardianta (2016:127), bahwa "Budaya perusahaan adalah himpunan dari kepercayaan, harapan, dan nilai-nilai yang dianut bersama oleh anggota perusahaan dan diwariskan dari satu generasi ke generasi berikutnya".

Disiplin Kerja. Rahayu Risya (2014:23), Berpendapat disiplin adalah "kemampuan mengendalikan perilaku yang berasal dari dalam diri seseorang sesuai dengan hal-hal yang telah diatur dari luar atau norma yang sudah ada". Dengan kata lain, disiplin dari segi psikologis merupakan perilaku seseorang yang muncul dan mampu menyesuaikan diri dengan aturan yang telah ditetapkan. Sedangkan menurut Edy Sutrisno (2016:89) Disiplin adalah "prilaku seseorang yang sesuai dengan peraturan, prosedur kerja yang ada atau disiplin adalah sikap, tingkah laku, dan perbuatan yang sesuai dengan peraturan dari organisasi baik tertulis maupun tidak tertulis.

Kinerja Karyawan. Menurut Mangkunegara (2015:67) "kinerja adalah hasil kerja secara kualitas dan kuantitas yang dicapai oleh seorang pegawai dalam melaksanakan tugasnya sesuai dengan tanggung jawab yang diberikan". Menurut Rivai (2013:604) "kinerja merupakan suatu istilah secara umum yang digunakan sebagai atau seluruh tindakan atau aktivitas dari suatu organisasi pada suatu periode dengan suatu referensi pada sejumlah standar seperti biaya masa lalu yang diproyeksikan dengan dasar efesiensi, pertanggung jawaban atau akuntabilitas manajemen dan sebagainya". 


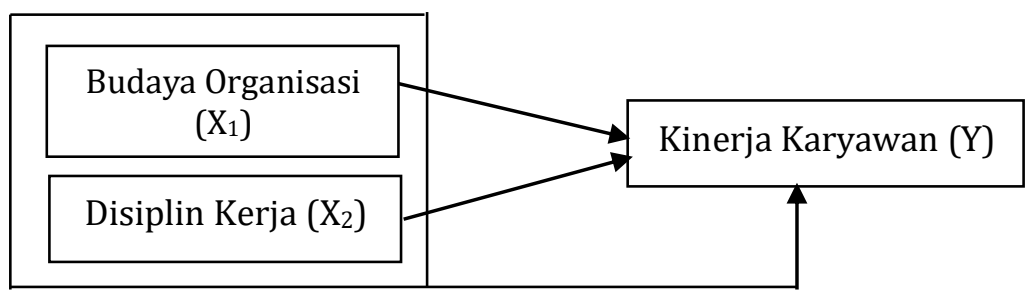

Gambar 1. Model Penelitian

\section{Hipotesis}

H01: $r=0$, Tidak terdapat pengaruh yang signifikan pada Budaya Organisasi terhadap Kinerja Karyawan.

Ha1 $: r \neq 0, \quad$ Terdapat pengaruh yang signifikan pada Budaya Organisasi terhadap Kinerja Karyawan.

H02: $r=0$, Tidak terdapat pengaruh yang signifikan pada Disiplin Kerja terhadap Kinerja Karyawan.

Ha2: $r \neq 0$, Terdapat pengaruh yang signifikan pada Disiplin Kerja terhadap Kinerja Karyawan.

H03 $: r=0$, Tidak terdapat pengaruh yang signifikan antara Budaya Organisasi dan Disiplin Kerja secara simultan terhadap Kinerja Karyawan.

Ha3 $: r \neq 0, \quad$ Terdapat pengaruh yang signifikan antara Budaya Organisasi dan Disiplin Kerja secara simultan terhadap Kinerja Karyawan.

\section{Metode Penelitian}

Penelitian ini dilakukan pada PT Eagle Indo Pharma yang bergerak di bidang farmasi beralamat di JL. Raya Prabu Siliwangi KM 1.1, Desa Alam Jaya, Kec. Jatiuwung Tangerang. Metode yang akan digunakan peneliti adalah metode kuantitatif dengan pendekatan deskriptif dan asosiatif kausal (sebab-akibat) karena adanya variabel- variabel yang akan ditelaah hubungannya serta tujuannya untuk menyajikan gambaran mengenai hubungan antara variabel-variabel yang diteliti, dimana pendekatan deskriptif menurut Sugiyono (2018:35) metode penelitian deskriptif dilakukan untuk mengetahui keberadaan variabel mandiri, baik hanya pada satu variabel atau lebih (variabel yang berdiri sendiri atau variabel bebas) tanpa membuat perbandingan variabel itu sendiri dan mencari hubungan dengan variabel lain.

Populasi dalam penelitian ini adalah seluruh karyawan yang bekerja pada PT. Eagle Indo Pharma-Tangerang terdapat jumlah karyawan di Divisi Likuid sebanyak 160 orang. Dengan menggunakan rumus Slovin maka jumlah sampel dalam penelitian ini berjumalah 62 responden. Teknik analisis data dengan menggunakan Uji validitas, uji reliabilitas, uji normalitas, uji multikolinearitas, uji heteroskedastisitas, uji regresi linier berganda, serta uji hipotesis.

Tabel 4. Operasional Variabel

\begin{tabular}{|c|c|c|c|}
\hline Variabel & Indikator & No. Butir & Skala \\
\hline \multirow{7}{*}{$\begin{array}{c}\text { Budaya } \\
\text { Organisasi (X1) } \\
\text { Sumber: Robbins } \\
\text { dan Judge (2015) }\end{array}$} & 1. Inovasi dan pengambilan & $1-2$ & \multirow[t]{7}{*}{ Likert } \\
\hline & 2. Perhatian terhadap detail & $3-5$ & \\
\hline & 3. Orientasi hasil & 6 & \\
\hline & 4. Orientasi orang & 7 & \\
\hline & 5. Orientasi tim & 8 & \\
\hline & 6. $\quad$ Keagresifan & 9 & \\
\hline & 7. Stabilitas & 10 & \\
\hline
\end{tabular}




\begin{tabular}{|c|c|c|c|}
\hline Variabel & Indikator & No. Butir & Skala \\
\hline \multirow{4}{*}{$\begin{array}{c}\text { Disiplin Kerja } \\
\text { (X2) } \\
\text { Sumber: } \\
\text { Singodimedjo } \\
\text { dalam Edy } \\
\text { Sutrisno } \\
(2016: 86)\end{array}$} & 1. Taat terhadap aturan waktu & $1-2$ & \multirow[t]{4}{*}{ Likert } \\
\hline & $\begin{array}{ll}\text { 2. } & \text { Taat tehadap peraturan } \\
\text { perusahaan }\end{array}$ & $3-4$ & \\
\hline & $\begin{array}{l}\text { 3. Taat terhadap aturan perilaku } \\
\text { dalam pekerjaan }\end{array}$ & $5-7$ & \\
\hline & $\begin{array}{l}\text { 4. Taat terhadap peraturan } \\
\text { lainnya }\end{array}$ & $8-10$ & \\
\hline \multirow{5}{*}{$\begin{array}{c}\text { Kinerja (Y) } \\
\text { Sumber : } \\
\text { Mangkunegara } \\
(2015)\end{array}$} & 1. Ketepatan penyelesaian tugas & $1-2$ & \multirow[t]{5}{*}{ Likert } \\
\hline & 2. Kesesuaian jam & $3-4$ & \\
\hline & 3. Tingkat Kehadiran & $5-6$ & \\
\hline & 4. Kerjasama antar karyawan & $7-8$ & \\
\hline & 5. Kepuasan Kerja & $9-10$ & \\
\hline
\end{tabular}

\section{Hasil Penelitian dan Pembahasan Uji Validitas}

Tabel 5. Hasil Uji Validitas

\begin{tabular}{|c|c|c|c|c|}
\hline No & Pernyataan & Rhitung & Rtabel & Keterangan \\
\hline \multicolumn{5}{|c|}{ Budaya Organisasi } \\
\hline 1 & Butir Pernyataan 1 & 0,958 & 0,2108 & Valid \\
\hline 2 & Butir Pernyataan 2 & 0,334 & 0,2108 & Valid \\
\hline 3 & Butir Pernyataan 3 & 0,958 & 0,2108 & Valid \\
\hline 4 & Butir Pernyataan 4 & 0,958 & 0,2108 & Valid \\
\hline 5 & Butir Pernyataan 5 & 0,430 & 0,2108 & Valid \\
\hline 6 & Butir Pernyataan 6 & 0,958 & 0,2108 & Valid \\
\hline 7 & Butir Pernyataan 7 & 0,319 & 0,2108 & Valid \\
\hline 8 & Butir Pernyataan 8 & 0,367 & 0,2108 & Valid \\
\hline 9 & Butir Pernyataan 9 & 0,958 & 0,2108 & Valid \\
\hline 10 & Butir Pernyataan 10 & 0,958 & 0,2108 & Valid \\
\hline \multicolumn{5}{|c|}{ Disiplin Kerja } \\
\hline 1 & Butir Pernyataan 1 & 0,973 & 0,2108 & Valid \\
\hline 2 & Butir Pernyataan 2 & 0,973 & 0,2108 & Valid \\
\hline 3 & Butir Pernyataan 3 & 0,410 & 0,2108 & Valid \\
\hline 4 & Butir Pernyataan 4 & 0,973 & 0,2108 & Valid \\
\hline 5 & Butir Pernyataan 5 & 0,973 & 0,2108 & Valid \\
\hline 6 & Butir Pernyataan 6 & 0,344 & 0,2108 & Valid \\
\hline 7 & Butir Pernyataan 7 & 0,973 & 0,2108 & Valid \\
\hline 8 & Butir Pernyataan 8 & 0,321 & 0,2108 & Valid \\
\hline 9 & Butir Pernyataan 9 & 0,973 & 0,2108 & Valid \\
\hline 10 & Butir Pernyataan 10 & 0,973 & 0,2108 & Valid \\
\hline \multicolumn{5}{|c|}{ Kinerja Karyawan } \\
\hline 1 & Butir Pernyataan 1 & 0,361 & 0,2108 & Valid \\
\hline 2 & Butir Pernyataan 2 & 0,996 & 0,2108 & Valid \\
\hline 3 & Butir Pernyataan 3 & 0,996 & 0,2108 & Valid \\
\hline
\end{tabular}




\begin{tabular}{|c|c|c|c|c|}
\hline 4 & Butir Pernyataan 4 & 0,996 & 0,2108 & Valid \\
\hline 5 & Butir Pernyataan 5 & 0,996 & 0,2108 & Valid \\
\hline 6 & Butir Pernyataan 6 & 0,996 & 0,2108 & Valid \\
\hline 7 & Butir Pernyataan 7 & 0,996 & 0,2108 & Valid \\
\hline 8 & Butir Pernyataan 8 & 0,996 & 0,2108 & Valid \\
\hline 9 & Butir Pernyataan 9 & 0,996 & 0,2108 & Valid \\
\hline 10 & Butir Pernyataan 10 & 0,996 & 0,2108 & Valid \\
\hline
\end{tabular}

Sumber : Data diolah (2020)

Berdasarkan data tabel di atas, dapat dilihat bahwa dari 30 butir pernyataan untuk variable Budaya organisasi, disiplin kerja dan kinerja karyawan disimpulkan bahwa butir pernyataan dinyatakan valid, hal ini dibuktikan dengan semua item-item pernyataan memiliki nilai corrected item total correlation lebih besar dari nilai rtabel 0,2108. Untuk itu kuesioner yang digunakan layak untuk diolah sebagai data penelitian.

\section{Uji Reliabilitas}

Tabel 6. Hasil Uji Reliabilitas

\begin{tabular}{|c|c|c|}
\hline Variabel & Cronchbach's Alpha & Keterangan \\
\hline Budaya Organisasi & 0,906 & Reliabilitas \\
\hline Disiplin & 0,938 & Reliabilitas \\
\hline Kinerja Karyawan & 0,985 & Reliabilitas \\
\hline
\end{tabular}

Sumber : Data diolah (2020)

Dari tabel 4.10 di atas menunjukkan bahwa nilai Cronbach's Alpha untuk variabel budaya organisasi (X1) adalah 0,906 dengan nilai lebih besar dari 0,60, pada variabel disiplin kerja (X2) adalah 0,938 dengan nilai lebih besar dari 0,60, dan pada variabel kinerja karyawan (Y) adalah 0,985 dengan nilai lebih besar dari 0,60. Berdasarkan hasil uji reliabilitas di atas diketahui semua variabel diperoleh nilai Cronbach's Alpha $>0,60$. Maka butir pernyataan dalam variabel tersebut dinyatakan reliabel.

\section{Uji Normalitas}

Tabel 7. Hasil Uji Normalitas

\begin{tabular}{|ll|r|}
\hline & & $\begin{array}{r}\text { Unstandardized } \\
\text { Residual }\end{array}$ \\
$\mathrm{N}$ & & 62 \\
Normal Parametersa,b & Mean & .0000000 \\
& Std. Deviation & .75471956 \\
Most Extreme & Absolute & .144 \\
& Positive & .144 \\
Kolmogorov-Smirnov Z & Negative & -.135 \\
Asymp. Sig. (2-tailed) & & 1.195 \\
& & .115 \\
\hline
\end{tabular}

Sumber : Data diolah (2020)

Berdasarkan tabel diatas maka dapat dilihat nilai Asymp. Sig (2-Tailed) yaitu 0,115 sehingga lebih besar dari 0,05 atau 0,115 >0,05, maka data pada penelitian ini berdistribusi normal. 
Tabel 8. Uji multikolinearitas Coefficients $^{\mathrm{a}}$

\begin{tabular}{|c|c|c|}
\hline \multirow{2}{*}{ Model } & \multicolumn{2}{|c|}{ Collinearity Statistics } \\
\hline & Tolerance & VIF \\
\hline Budaya Organisasi & .997 & 1.003 \\
\hline Disiplin & .997 & 1.003 \\
\hline
\end{tabular}

a. Dependent Variable: Kinerja Karyawan

Sumber : Data diolah (2020)

Dari tabel di atas dapat diketahui bahwa nilai Variance Inflation Factor (VIF) untuk variable budaya organisasi dan disiplin kerja sebesar 1,003. Artinya, nilai VIF lebih kecil dari pada 10. Dengan demikian, dapat disimpulkan bahwa tidak terjadi gejala multikolinearitas di antara variabel bebas.

\section{Uji Autokorelasi}

Tabel 9. Uji Autokorelasi

Model Summaryb

\begin{tabular}{|c|c|c|c|c|c|}
\hline Model & $\mathrm{R}$ & $\mathrm{R}$ Square & $\begin{array}{c}\text { Adjusted } \\
\text { R Square }\end{array}$ & $\begin{array}{c}\text { Std. Error of } \\
\text { the Estimate }\end{array}$ & $\begin{array}{c}\text { Durbin- } \\
\text { Watson }\end{array}$ \\
\hline 1 & $.833 \mathrm{a}$ & .694 & .685 & .766 & 1.744 \\
\hline
\end{tabular}

a. Predictors: (Constant), Disiplin Kerja, Budaya Organisasi

b. Dependent Variable: Kinerja Karyawan

Sumber : Data diolah (2020)

Dari tabel di atas dapat diketahui bahwa nilai Durbin-Watson (DW) yang dihasilkan dari model regresi adalah 1,744. Sedangkan dari tabel DW dengan signifikansi 5\% dan jumlah data $(\mathrm{n})=62$ serta $\mathrm{k}=2$ ( $\mathrm{k}$ adalah jumlah variabel independen), sehingga diperoleh nilai $\mathrm{dL}$ sebesar 1,5232 dan dU sebesar 1,6561 (lihat pada lampiran tabel dw). Dari perhitungan tersebut bahwa nilai DW sebesar 1,744 terletak diantara dU dan (4-dU) sebesar 1,6561 dan 2,3439 ( $\mathrm{dU}<\mathrm{dw}<4-\mathrm{dU}$ ) maka dapat disimpulkan bahwa tidak ada autokorelasi dalam model regresi yang digunakan dalam penelitian ini.

\section{Uji Heteroskedastisitas}

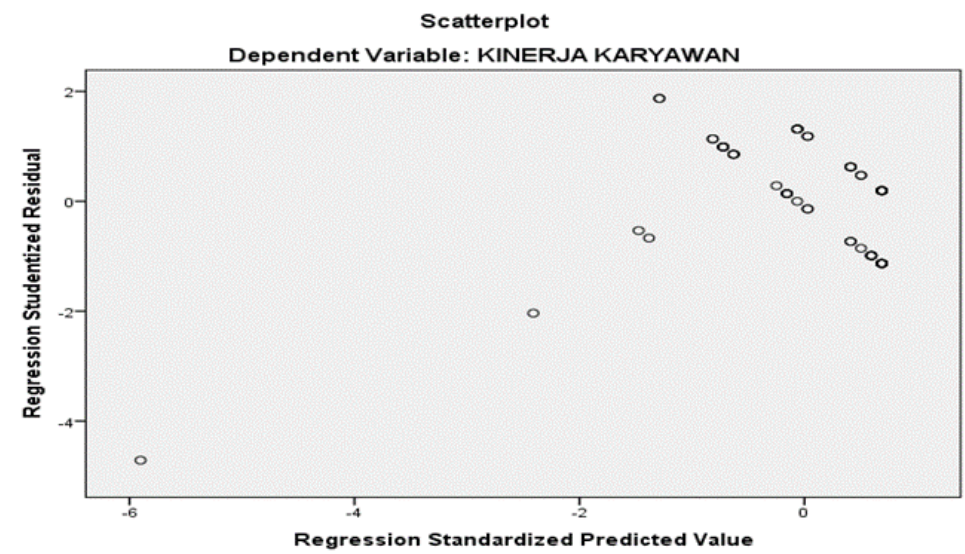

Gambar 2. Heteroskedastisitas

Pada gambar diatas, dapat dilihat bahwa titik-titik pada grafik scatter plot mempunyai pola penyebaran yang jelas dan titik-titik tersebut menyebar diatas dan dibawah angka 0 pada sumbu Y, dengan demikian hal ini menunjukkan bahwa tidak terjadi heterokedaktisitas. 


\section{Analisis Regresi Linier Sederhana}

Tabel 10. Regresi Linier Sederhana Variabel Budaya Organisasi $\left(X_{1}\right)$ terhadap Variabel Kinerja Karyawan (Y)

\begin{tabular}{|c|c|c|c|c|c|c|}
\hline \multirow{2}{*}{\multicolumn{2}{|c|}{ Model }} & \multicolumn{2}{|c|}{ Unstandardized } & Standardized & \multirow{2}{*}{$\mathrm{T}$} & \multirow{2}{*}{ Sig. } \\
\hline & & B & Std. Error & Beta & & \\
\hline \multirow{2}{*}{1} & (Constant) & -12.312 & 1.793 & & -6.866 & .000 \\
\hline & Budaya Organisasi & 1.282 & .042 & .970 & 30.719 & .000 \\
\hline
\end{tabular}

Sumber : Data diolah (2020)

Berdasarkan hasil perhitungan tersebut maka dapat diperoleh persamaan regresi linear sederhana sebagai berikut : $\mathrm{Y}=-12,312+1,282 \mathrm{X}$. Artinya Nilai konstanta menunjukan bahwa apabila budaya organisasi bernilai 0 (nol) maka kinerja karyawan terjadi sebesar 12,312. Nilai koefisien budaya organisasi sebesar 1,282 menunjukan bahwa setiap kenaikan $1 \%$ pada budaya organisasi akan diikuti dengan peningkatan kinerja karyawan sebesar 1,282. Maka dapat dikatakan bahwa arah pengaruh variabel budaya organisasi terhadap kinerja karyawan adalah positif.

\section{Tabel 11. Regresi Linier Sederhana Variabel Disiplin Kerja $\left(X_{2}\right)$} terhadap Variabel Kinerja Karyawan (Y)

\begin{tabular}{|c|l|r|r|r|r|r|}
\hline \multirow{2}{*}{ Model } & \multicolumn{2}{|c|}{$\begin{array}{c}\text { Unstandardized } \\
\text { Coefficients }\end{array}$} & \multicolumn{2}{c|}{$\begin{array}{c}\text { Standardized } \\
\text { Coefficients }\end{array}$} & \multirow{2}{*}{$\mathrm{t}$} & \multirow{2}{*}{ Sig. } \\
\cline { 3 - 5 } \multicolumn{2}{|c|}{} & B & Std. Error & \multicolumn{1}{c|}{ Beta } & & \\
\hline \multirow{2}{*}{1} & (Constant) & -7.461 & 1.237 & & -6.032 & .000 \\
\cline { 2 - 7 } & Disiplin Kerja & 1.173 & .029 & .982 & 40.651 & .000 \\
\hline
\end{tabular}

Sumber : Data diolah (2020)

Berdasarkan hasil perhitungan tersebut diperoleh persamaan regresi linear sederhana sebagai berikut: $\mathrm{Y}=-7,461+1,173 \mathrm{X}$. Artinya Nilai konstanta menunjukan bahwa apabila disiplin kerja bernilai 0 (nol) maka kinerja karyawan terjadi sebesar -7,461. Nilai koefisien disiplin kerja sebesar 1,173 menunjukan bahwa setiap kenaikan 1\% pada disiplin kerja akan diikuti dengan peningkatan kinerja karyawan sebesar 1,173. Maka dapat dikatakan bahwa arah pengaruh variabel disiplin kerja terhadap kinerja karyawan adalah positif.

\section{Analisis regresi linier berganda}

Tabel 12. Hasil analisis regresi linier berganda

\begin{tabular}{|c|c|c|c|c|c|c|}
\hline \multirow{2}{*}{\multicolumn{2}{|c|}{ Model }} & \multicolumn{2}{|c|}{$\begin{array}{c}\text { Unstandardized } \\
\text { Coefficients }\end{array}$} & $\begin{array}{l}\text { Standardized } \\
\text { Coefficients }\end{array}$ & \multirow[t]{2}{*}{$t$} & \multirow[t]{2}{*}{ Sig. } \\
\hline & & $\mathrm{B}$ & Std. Error & Beta & & \\
\hline \multirow[t]{3}{*}{1} & (Constant) & 7.145 & 5.054 & & 1.414 & .162 \\
\hline & Budaya Organisasi & .105 & .085 & .084 & 1.229 & .223 \\
\hline & Disiplin Kerja & .749 & .062 & .825 & 12.100 & .000 \\
\hline
\end{tabular}

Sumber : Data diolah (2020)

Dari tabel diatas diperoleh persamaan regresi berganda berikut:

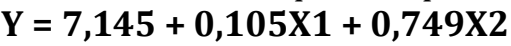

1) Nilai konstanta menunjukan bahwa apabila budaya organisasi dan disiplin kerja bernilai 0 (nol) maka Kinerja karyawan terjadi sebesar 7,145.

2) Nilai koefisien budaya organisasi memiliki nilai positif sebesar 0,105 menunjukkan bahwa setiap kenaikan 1 skor pada budaya organisasi akan diikuti dengan peningkatan kinerja karyawan sebesar 0,105.

3) Nilai koefisien disiplin kerja memiliki nilai positif sebesar 0,749 menunjukkan bahwa setiap kenaikan 1 skor pada disiplin kerja akan diikuti dengan peningkatan kinerja karyawan sebesar 0,749 . 


\section{Koefisien Determinasi}

Tabel 13. Hasil Koefisien Determinasi

Model Summaryb

\begin{tabular}{|c|c|c|c|c|c|}
\hline Model & $\mathrm{R}$ & $\mathrm{R}$ Square & $\begin{array}{c}\text { Adjusted } \\
\text { R Square }\end{array}$ & $\begin{array}{c}\text { Std. Error of } \\
\text { the Estimate }\end{array}$ & $\begin{array}{c}\text { Durbin- } \\
\text { Watson }\end{array}$ \\
\hline 1 & $.833 \mathrm{a}$ & .694 & .685 & .766 & 1.744 \\
\hline
\end{tabular}

a. Predictors: (Constant), Disiplin Kerja, Budaya Organisasi

b. Dependent Variable: Kinerja Karyawan

Sumber : Data diolah (2020)

Berdasarkan tabel di atas dapat diketahui bahwa nilai $R$ Square sebesar 0,694, artinya variabel budaya organisasi (X1) dan disiplin kerja (X2) secara bersama-sama memiliki kontribusi pengaruh sebesar $69,4 \%$ terhadap kinerja karyawan (Y). Sedangkan sisanya sebesar 30,6\% dipengaruhi oleh faktor lain yang tidak diteliti dalam penelitian ini.

\section{Uji Hipotesis}

Untuk pengujian pengaruh antara variabel Budaya organisasi (X1) dan Disiplin kerja (X2) terhadap Kinerja Karyawan (Y) dapat dilakukan dengan uji statistik t (uji secara parsial). Dalam penelitian ini digunakan kriteria signifikan $5 \%(0,05)$ dengan membandingkan dengan yaitu sebagai berikut:

1) Jika t hitung $<$ t tabel : berarti diterima ditolak $(\alpha=5 \%)$

2) Jika t hitung $>$ t tabel : berarti ditolak diterima $(\alpha=5 \%)$

Tabel 14. Hasil Uji t Budaya Organisasi

\begin{tabular}{|c|c|r|r|r|r|r|}
\hline \multicolumn{2}{|c|}{ Model } & \multicolumn{2}{c|}{ Unstandardized } & \multicolumn{1}{c|}{ Standardized } & \multirow{2}{*}{ T } & \multirow{2}{*}{ Sig. } \\
\cline { 2 - 4 } & \multicolumn{1}{|c|}{ B } & Std. Error & \multicolumn{1}{c|}{ Beta } & & \multicolumn{1}{c|}{} \\
\hline \multirow{2}{*}{1} & (Constant) & -12.312 & 1.793 & & -6.866 & .000 \\
\cline { 2 - 5 } & Budaya Organisasi & 1.282 & .042 & .970 & 30.719 & .000 \\
\hline
\end{tabular}

Sumber : Data diolah (2020)

Bersadarkan tabel di atas diperoleh nilai thitung $>$ ttabel $(30,719>2,001)$ hal tersebut juga diperkuat dengan nilai signifikansi 0,000 $<0,05$. Dengan demikian HO ditolak dan Ha diterima. Artinya budaya organisasi (X1) berpengaruh signifikan terhadap kinerja karyawan (Y) di Divisi Likuid pada PT.Eagle Indo Pharma- Tangerang.

Tabel 15. Hasil Uji t Disiplin Kerja

\begin{tabular}{|c|l|r|r|r|r|r|}
\hline \multirow{2}{*}{ Model } & \multicolumn{2}{|c|}{$\begin{array}{c}\text { Unstandardized } \\
\text { Coefficients }\end{array}$} & $\begin{array}{c}\text { Standardized } \\
\text { Coefficients }\end{array}$ & \multirow{2}{*}{ t } & \multirow{2}{*}{ Sig. } \\
\cline { 3 - 5 } \multicolumn{2}{|c|}{} & B & Std. Error & \multicolumn{1}{c|}{ Beta } & & \\
\hline \multirow{2}{*}{1} & (Constant) & -7.461 & 1.237 & & -6.032 & .000 \\
\cline { 2 - 7 } & Disiplin Kerja & 1.173 & .029 & .982 & 40.651 & .000 \\
\hline
\end{tabular}

Sumber : Data diolah (2020)

Berdasarkan tabel di atas diperoleh nilai thitung $>$ ttabel $(40,651>2,001)$ hal tersebut juga diperkuat dengan nilai signifikansi $0,000<0,05$. Dengan demikian H0 ditolak dan Ha diterima. Artinya disiplin kerja (X2) berpengaruh signifikan terhadap kinerja karyawan (Y) di Divisi Likuid pada PT.Eagle Indo Pharma- Tangerang. 
Tabel 16. Hasil Uji F

ANOVAa

\begin{tabular}{|l|l|r|r|r|r|c|}
\hline \multicolumn{2}{|c|}{ Model } & $\begin{array}{c}\text { Sum of } \\
\text { Squares }\end{array}$ & \multicolumn{1}{c|}{ df } & Mean Square & F & Sig. \\
\hline \multirow{2}{*}{1} & Regression & 87.905 & 2 & 43.952 & 74.894 & $.000 \mathrm{~b}$ \\
\cline { 2 - 7 } & Residual & 38.733 & 66 & .587 & & \\
\cline { 2 - 7 } & Total & 126.638 & 68 & & & \\
\hline
\end{tabular}

a. Dependent Variable: Kinerja Karyawan

b. Predictors: (Constant), Disiplin Kerja, Budaya Organisasi

Sumber : Data diolah (2020)

Berdasarkan tabel di atas diperoleh nilai Fhitung $>$ Ftabel atau $(74,894>3,15)$ hal ini juga diperkuat dengan nilai probability signifikansi sebesar 0,000 $<0,05$. Dengan demikian H0 ditolak dan Ha diterima. Dapat disimpulkan bahwa budaya organisasi (X1) dan disiplin kerja (X2) berpengaruh signifikan secara simultan terhadap kinerja karyawan (Y) di Divisi Likuid pada PT.Eagle Indo Pharma-Tangerang.

\section{Kesimpulan}

Budaya organisasi (X1) berpengaruh signifikan terhadap kinerja karyawan (Y) di Divisi Likuid pada PT.Eagle Indo Pharma-Tangerang. Hal tersebut dapat dilihat dari hasil pengujian hipotesis secara parsial (uji t) yang dimana diperoleh nilai thitung $>$ ttabel ttabel $(30,719>1,67109$ hal tersebut juga diperkuat dengan nilai signifikansi $0,000<0,05$. Dengan demikian H0 ditolak dan Ha diterima. Disiplin kerja (X2) berpengaruh signifikan terhadap kinerja karyawan (Y) di Divisi Likuid pada PT.Eagle Indo Pharma-Tangerang. Hal tersebut dapat dilihat dari hasil pengujian hipotesis secara parsial (uji t) diperoleh nilai thitung $>$ ttabel $(40,651>1,67109)$ hal tersebut juga diperkuat dengan nilai signifikansi $0,000<0,05$. Dengan demikian H0 ditolak dan Ha diterima. Budaya Organisasi (X1) dan Disiplin Kerja (X2) berpengaruh signifikan secara simultan terhadap kinerja karyawan (Y) di Divisi Likuid pada PT.Eagle Indo Pharma-Tangerang. Hal tersebut dapat dilihat dari hasil pengujian hipotesis secara simultan (uji f) diperoleh nilai Fhitung $>$ Ftabel atau $(74,894>3,15$ ) hal ini juga diperkuat dengan nilai probability signifikansi sebesar $0,000<0,05$. Dengan demikian H0 ditolak dan Ha diterima.

\section{Daftar Pustaka}

Badriyah, M. (2015). Manajemen Sumber Daya Manusia. Cetakan 1. Bandung: CV Pustaka Setia.

Edison, Emron, dkk. (2016). Manajemen Sumber Daya Manusia. Cetakan Kesatu April 2016. Bandung: Alfabeta.

Edy, Sutrisno. (2014). Manajemen Sumber Daya Manusia. Jakarta: Penerbit KencanaPrenda Media Group.

A.A. Anwar Prabu Mangkunegara. (2015). Manajemen Sumber Daya Manusia. Bandung: Remaja Rosdakarya.

Hasibuan, Malayu. (2014). Manajemen Sumber Daya Manusia. Jakarta: Bumi Aksara.

Veithzal Rivai. (2015). Manaemen Sunber Daya Manusia. Edisi ke-6. PT. Raja Grafindo Persada, Depok, 16956.

Terry, George R dan Rue, Leslie W. (2015). Dasar-dasar Manajemen. Cetakan ke-16. Jakarta:PT. Bumi Aksara.

Wardiah. (2016). Teori Perilaku dan Budaya Organisasi. Bandung: CV Pustaka Setia.

Robbins, Stephen P dan Timoty A Judge. (2014). Perilaku Organisasi. Jakarta: Salemba Empat. 
Robbins, Stephen P dan Timoty A Judge. (2015). Perilaku Organisasi. Jakarta: Salemba Empat.

Edy Sutrisno. (2016). Manajemen Sumber Daya Manusia. Cetakan ke-8. Jakarta: Prenda Media Group.

Kasmir. (2016). Analisis Laporan Keuangan. Jakarta: Raya Grafindo Persada.

Setiawan F dan Kartika Dewi A. (2014). Pengaruh Kompensasi dan Lingkungan Kerja Terhadap Kinerja Karyawan pada CV. Berkat Anugrah. E-Jurnal Manajemen Universitas Udayana.3 (5).

Sugiyono. (2015). Metode Penelitian Pendidikan (Pendekatan Kuantitatif, Kualitatif dan $R$ $\& D)$. Penerbit CV. Alfabeta:Bandung.

Ghozali, I. (2016). Aplikasi Analisis Multivariete Dengan Program IBM SPSS 23. Semarang: Badan Penerbit Universitas Diponegoro

Sugiyono. (2016). Metode Penelitian Kuantitatif, Kualitatif, dan R\&D. Bandung: Alfabeta.

Sugiyono. (2018). Metode Penelitian Kuantitatif, Kualitatif, dan R\&D. Bandung: Alfabeta.

Suntoyo, D. (2016). Metodologi Penelitian Akuntansi. Bandung: PT. Rafika Aditama.

Kasmir. (2016). Manajemen Sumber Daya Manusia. Jakarta: PT. Raja Grafindo Persada.

Sinambela, L. P. (2016). Manajemen Sumber Daya Manusia. Jakarta: PT. Bumi Aksara.

Wibowo. (2015). Manajemen Kinerja. Jakarta: PT. Raja Grafindo Persada. 